\title{
Research on the Deeper Learning based on O2O Flip-Classroom
}

\author{
Guixin Zhao \\ School of Information Qilu University of Technology Jinan, 250353,China \\ email: guixin79@126.com
}

Keywords: Deeper Learning; Filp-Classroom; WeChat

\begin{abstract}
Deeper Learning is an active, critical way of learning and is a very important research topic in today's education. Flip-classroom is a new teaching model that can fully reflect the initiative of students, and fully mobilize the enthusiasm of students. This paper constructs the system architecture of $\mathrm{O} 2 \mathrm{O}$ Flip-Classroom based on the WeChat and introduces the function of each component in the architecture according the goal of deeper learning that is to develop students deeper learning ability.

Introduction

With the rapid development of information technology, the continuous globalization of the world economy, the complexity and diversification of social life, a new generation of students are faced with more complex and rapidly changing living and working environment. The rise of the deeper learning is that people consciously respond to the knowledge economy, lifelong education, quality education concept of basic education development requirements of the results, therefore, how to promote the deeper learning and cultivate the students' deep learning ability will be the important subject of the future educational reform and development.
\end{abstract}

\section{Deeper Learning}

Deeper learning is a changing concept. Early in the study, most researchers believed that deeper learning is a learning method compared to surface learning. Biggs thought that deeper learning involves high-level or active cognitive processing, but the corresponding surface learning uses low-level cognitive processing. Deeper learning means that students learn in order to understand, main performances are the content of the critical understanding of learning, emphasizing the connection between previous knowledge and experience, focusing on logical relations and conclusions of the evidence[1]。

With the development of the deeper learning, the researchers have shifted from the methods of the deeper learning to the progress of deeper learning. Brans-ford, Brown, and Cocking argued that the deeper learning promotes long-term retention by allowing students to truly understand what they are learning, thereby enables students to extract the knowledge they learn to solve new question in different situation [2]. The US National Research Council argues that deeper learning is the process in which an individual applies the learned knowledge from one context to another, That is to say migration. Researchers with learning outcomes say that the goal of deeper learning is to develop students' core competencies to adapt to social development [3]. The American Association for the Study of Excellence defines the deeper learning by delivering a rich core of learning content to students by the innovative way, guiding them to effectively learn and be able to apply what they have learned in practice, emphasizing the deeper learning will be standardized testing and grasp communication, collaboration, self-learning ability etc to connect [4].

On the basis of literature research and widely soliciting expert opinions, the William and Flora Hewlett Foundation defines in-depth learning as follows: Deeper learning is the necessary competencies must-haved by students who are capable of working and living in the 21st century. They provide students with the flexibility to grasp and understand subject knowledge and apply them to solve problems in the classroom and in the future, including mastering core disciplines, The basic ability of thinking and complex problem solving, teamwork, effective communication, learn to learn, study perseverance six dimensions [5]. As can be seen, the definition explains mainly 
deeper learning from the perspective of the learning results. The mastering core disciplinary knowledge refers to enabling students to understand the core disciplines and to move them to other situations. The critical thinking and the ability to solve complex problems is to enable students to discover and solve problems by collecting the core subject knowledge, application technology using data analysis, statistical reasoning, scientific inquiry, creativity and non-linear thinking and perseverance. The teamwork ability refers that students can collaboratively discover and creatively address challenges from learning, social, professional, and personal. The effective communication skills refer that students can enable to organize clearly their data, discover and think. The Learning to learn ability is that students can monitor and guide their own learning. The learning Persistence refers that students can develop positive learning attitudes that enhance their learning stamina and facilitate their effective learning, and students are able to find ways to overcome difficulties in fulfilling their tasks to meet learning objectives and high quality work.

Students' deeper learning ability can be improved through the design or redesign of the school teaching strategies, teaching structure, the school culture. The experimental data analysis shows that the deep learning strategies and approaches adopted by the experimental schools are divided into two parts: one is to reinvent the classroom teaching design, specifically from to from the clear teaching objectives, curriculum development, classroom teaching and teaching evaluation the four aspects to redesign, Second is to change the school structure and culture, specifically include the flexible arrangements class, to set up advisory classes and to support the development of individualized school culture.

\section{The 020 flip-classroom}

Flip-classroom is to re-adjust the time inside and outside the classroom, the learning decision right change from the teacher to the students. In this education model, students in the classroom can focus more on proactive project-based learning, and work together to address the localization or globalization challenge of and other problems faced by real world in order to gain a deeper understanding. Teachers no longer take up classroom time to teach information, which requires students to complete self-study after school. They can watch video lectures, listen to podcasts, read enhanced e-books, but also discuss with other students in the network and access the necessary materials online at any time. Teachers can have more time to communicate with everyone. After the lesson, the students plan independently their own learning content, learning the rhythm, style and the way in which knowledge is presented. Teachers use the teaching method and collaboration method to meet the needs of students and promote their personalized learning. The purpose is to enable students to obtain more real learning though practice. The flip-classroom model is a part of the big educational campaign. It has some overlapping with blended learning, exploratory learning, and other teaching methods and tools at the meaning, which all attempt to make learning more flexible, proactive, and so that students are more involved. Internet era, students learn a rich online course without going to school to listen to the teachers. Internet, especially mobile Internet birth "flip classroom" teaching mode. "Flip classroom" Completely subversive the traditional classroom teaching structure and teaching process based on printing, which will lead to teacher roles, curriculum, management and a series of changes.

Student learning process generally includes two stages: "knowledge transfer" and "absorption internalization". Flip classroom adjust "knowledge transfer" stage to out of the classroom and transfer the "internalization of knowledge" stage in the classroom, which is the opposite of the traditional classroom.

When the flip-classroom encounter $\mathrm{O} 2 \mathrm{O}$, both the teaching reform and the learning experience are injected a new vitality. The innovation and improvement of flip-classroom implementation being good at using the internet thinking can effectively solve the existing shortcomings of the traditional classroom teaching. In the flip-classroom model, students use the teaching videos and related learning materials provided by teachers to carry out knowledge learning, teachers with online guidance, teachers organize students to discuss in the classroom, coach and answer some 
question targeted. This teaching method will help students to promote the absorption of knowledge and the internalization, which is the advantages of flip-classroom compared to the traditional classroom.

The difference of flip classroom and traditional teaching methods:

(a) Students mastered the initiative of learning. In the O2O flip classroom, students can choose learning time and learning rhythm according to their own situation, can access specific information or play the teaching video According to themselves needs. In traditional teaching, teachers control the entire learning process. Students complete the homework according to the guidance of teachers and are asked to learn, are almost entirely controlled by the teacher.

(b) Enhance the direct interaction between teachers and students. More importantly, this interaction is a three-dimensional interaction, not only the face-to-face interaction in the classroom, but also is the online interaction on the network. In the $\mathrm{O} 2 \mathrm{O}$ flip classroom, teachers converse from the classroom lecturers into a learning resource presentation, interacts with students anytime and anywhere through the mobile teaching platform and a variety of mobile terminals, but also help teachers understand the students and can be more specific to explain the focus and difficulty in the classroom teaching. For students, the $\mathrm{O} 2 \mathrm{O}$ flip classroom provides with a mobile learning platform and the opportunities of exchange, let students to share learning outcomes and learning experience and learn collaborative learning.

(c) Changed the way of lectures 。The traditional way of teaching, teachers explain the knowledge and impart knowledge to the students continuously the student' base and the acceptation ability are different, which will lead to some students tired of learning in the classroom, some students can not fully understand. Flip classroom can allow students to learn their own knowledge before class, repeat their study according to their own situation, reduce the teacher' repeating the lectures in the classroom and improve classroom efficiency.

(d) Changed the teacher's task. Flip classroom lets teachers to be the organizer of the classroom, and highlights the student's subjectivity. Flip classroom more focuses on students' learning ability, learning habit, thinking style, and cooperation spirit and is more line with the training mode of learning society.

(e) Improved the operating mode of the classroom. O2O flip classroom compared with the traditional classroom model, the key links have the targeted improvements before, during and after the classroom. The primary purpose of the flip classroom is to cultivate students' autonomous learning ability, promote students' individualized growth, and enhance students' learning efficiency. Therefore, the flip classroom mode can fully change teachers' education concept and teaching behavior, let teaching adopt to learning, assist learning and service learning.

\section{The o2o flip classroom system Based on Wechat}

In order to improve students' ability of deep study, we must rebuild the classroom teaching design. From the students 'cognition, interpersonal relationship and individual ability, we should redesign the teaching in order to adapt to the cultivation of students' deeper learning ability. We must transform the school structures and culture including flexible arrangements for class hours, opening the consultation classes and a school culture that supports personalized development.

(a) The teacher' offline focus work is to re-design the teaching objectives meeting the requirements of deeper learning. From the cognitive field the teachers draw up the teaching objectives in order to develop students to better grasp the core knowledge disciplines and develop students' critical thinking, specifically how to make students learn the content and the real world, how to find and use information, how to solve problems and critical thinking, how to identify facts and how to reason and analyze problems. From the interpersonal areas the important goal of the teaching is to develop students' effective communication and teamwork ability. In the personal field the goal of teaching is to cultivate students' learning perseverance and learn how to learn, self-efficacy, adaptability, self-learning, self-management and self-motivation to cultivate students' lifelong learning concept. Secondly, teachers need to provide appropriate curriculum and 
teaching content, record appropriate micro - video and formulate pre-classroom work that attract students to learn actively in order to make students reach the goal of deeper learning. Third, the teacher draws us the development of evaluation system in line with the deeper learning. The student's learning achievement is the only goal of evaluation is not. The effective communication skills and teamwork ability is a basis for evaluation of students. Such as: the teacher gives homework to a team in the middle of the semester so that the team members can complete the job collaboratively which is evaluated in the classroom. Fourth, the teacher teaches carefully according student evaluation of online learning. Students can master the process of learning to the problem. The teacher can be targeted to explain the learning. Fifth, the teacher organizes students to discuss question deeply in the classroom, so that make students thoroughly and in-depth grasp of the knowledge in this lesson and learn to master.

(b) Teachers' online management. First, the teacher pushes the micro-video to the WeChat platform for students. Second, the teacher distribute of pre-class learning tasks so that students can learn new knowledge to attract students to actively learn the contents of this lesson. Third, divides online students into group to helps students participate in online discussions and organizes students to participate actively in online discussions. Fourth, publish online test content and organize students to conduct online tutorial evaluation.

(c) Students' online tasks. The first is to receive Preview tasks according to their academic situation, personal interests, expertise, developments needing of personalized learning. The students can access to network resources to complete self-learning through the network. Second, the students watch online micro-video, third, they participate in the online discussion which is organized by teacher. Fourth, they do some test problems to test their preview result.

(d) Students of the offline tasks: first, they go to the classroom to listen to the teacher in order to grasp the difficulties and focus. Second, to participate in the deeper discussion in the classroom. The students can thoroughly grasp the new knowledge to further deepen the internalization of knowledge after the deeper discussion. Third, to complete collaboratively the homework arranged by teachers and demonstrate their outcomes by lecturing.

The online teaching space can be expanded through the implementation of O2O flip classroom. According to the teaching concept of "learning before teaching", it cultivates students' 'independent thinking and learning autonomy, give full play to the students' individual specialty, promote individual learning, improve students' learning ability to use digital, stimulate students' learning enthusiasm and improve learning efficiency. At the same time, the introduction of O2O flip classroom model, will promote teachers' innovation and change teaching behavior, let teaching adapt to learning, teaching assists learning and teaching service learning. O2O flip classroom can also amplify rapidly the effect of classroom learning, and enhance the online and offline joint drainage, bring high viscosity of the learners, thereby enhance the comprehensive impact of classroom teaching implementation.

\section{Conclusion}

In the system $\mathrm{O} 2 \mathrm{O}$ flip based on WeChat, the student's central position can be enhanced - in the learning environment and interactive activities, students will be encouraged to actively participate in learning activities and actively share the learning outcomes. The communication between teachers and students will become much smoother. It is much easier for students to acquire course resources and learn feedback. The focus of teaching managers not only focus on the release of resources and supervision of learning progress, but have more energy to create the Internet learning environment, create a good learning atmosphere and encourage students to participate in the initiative. 


\section{Acknowledgement}

In this paper, the research was sponsored by the teaching research project of QiLu University of Technology (Project No. 2015024) and by the teaching research project of QiLu University of Technology (Project No. 2013024).

\section{References}

[1] Beatte v.,Clooins,B\&Mc Innes B..Deep and surface learning: A simple or simplistic dichotomy? Accounting Education,1997 (6) 1-12.

[2] Bransford J.,Brown A. \&Cocking R.How people learn:Brain,mind,experience and school [M]. Washington.DC:National Academy Press,2000:65.

[3]National Research Council. Education for life and work: Developing transferable knowledge and skill in the 21st century [M].Washington, DC: National Academies Press,2012.

[4]Alliance for Excellent Education.A time for deeper leaning Preparing students for a changing world [R]. Washington: Alliance for Excellent Education.2011.

[5]William and Flora Hewlett Foundation. Deeper learning competencies[ DB/OL].[2016-04-15].http://www.hewlett.org/uploads/documents/Deeper_leaning_ Defined_April_2013.pdf. 